Artigo

\title{
"Falo para guardar 8 na cabeça e contar nos dedinhos o restante": estratégias de resolução de problemas adotadas pelas famílias durante a pandemia

\author{
"I ask you to imagine 8 and count the rest on your fingers": problem-solving strategies \\ adopted by families during the pandemic
}

"Hablo para tener 8 en la cabeza y contar el resto con los dedos": estrategias de resolución de problemas adoptadas por las familias durante la pandemia

\author{
Brenda Cristina Antunes ${ }^{1}$ \\ (iD) [0000-0002-2545-5760] \\ Klinger Teodoro Ciríaco ${ }^{2}$ \\ (iD) [0000-0003-1694-851X] \\ Francieli Aparecida Prates dos Santos ${ }^{3}$ \\ [0000-0002-2909-9871]
}

\begin{abstract}
Resumo
Pretendemos analisar, neste paper, saberes matemáticos mobilizados em estratégias de ensino adotadas por mães quando do auxílio nas tarefas escolares, especificamente de seus filhos, matriculados em turmas do ciclo da alfabetização (1으 ao 3 ano) de uma escola pública localizada em São Carlos-SP. Fruto de uma pesquisa institucional, em termos de justificativa, destacamos a importância do conhecimento informal dos sujeitos letrados, muitas vezes baseado em ações que permeiam a vida cotidiana. Os dados foram coligidos a partir da abordagem qualitativa, por meio de entrevistas semiestruturadas virtuais, devido ao distanciamento social. Os resultados demonstram que estas mulheres-mães, ao que tudo indica, para além do ato da coragem de assumirem mais um afazer, em meio a tantos que se responsabilizam em seus lares, conseguem driblar as dificuldades e recorrem a estratégias fundamentais para pensar matematicamente, mesmo não sendo convencionais. A exemplo da prática de contagem nos dedos (visualização), fazer cálculos "de cabeça" (cálculo mental) e exploração de jogos na internet (recurso à tecnologia), tendências que buscam desenvolver autonomia na aprendizagem. Em síntese, identificar, descrever e analisar qual é o contributo central deste auxílio em casa para a aprendizagem matemática das crianças representa, na leitura interpretativa que fazemos deste momento histórico vivenciado desde 2020, enxergar os espaços dos círculos das "culturas matemáticas" que permeiam os lares brasileiros.
\end{abstract}

Palavras-chave: Ensino remoto. Educação Matemática. Práticas de numeramento.

\section{Abstract}

We intend to analyze, in this paper, mathematical knowledge mobilized in teaching strategies adopted by mothers during the help of school tasks, specifically for their children, enrolled in classes of the

\footnotetext{
${ }^{1}$ bren_antunes@hotmail.com, Licenciada em Pedagogia, Mestranda em Educação, Universidade Federal de São Carlos (UFSCar), São Carlos/SP/Brasil.

2 klinger.ciriaco@ufscar.br, Doutor em Educação, Professor Adjunto do Departamento de Teorias e Práticas Pedagógicas (DTPP), Universidade Federal de São Carlos (UFSCar), São Carlos/SP/Brasil.

${ }^{3}$ francieli.prates.fp@gmail.com, Mestra em Educação Matemática, Pedagoga, Universidade Federal de Mato Grosso do Sul (UFMS), Campo Grande/MS/Brasil.
} 
literacy cycle (1st to 3rd year) of a public school located in São Carlos, Brazil. As a result of institutional research, in terms of justification, we highlight the importance of informal knowledge of literate subjects, often based on actions that permeate everyday life. The data were analyzed using the qualitative approach, through virtual semi-structured interviews, due to social distance. The results demonstrate that these women / mothers, it seems, in addition to the act of courage to take on another task, among so many who take responsibility in their homes, manage to circumvent the difficulties and resort to fundamental strategies to think mathematically, even though they are not conventional. We exemplify the practice of counting on fingers (visualization), calculating on your head (mental calculation) and exploring games on the internet (using technology), trends that seek to develop autonomy in learning. In summary, the research identifies, describes and analyzes what is the central contribution of this aid at home to children's mathematical learning. In the interpretative reading that we make of this historic moment experienced in 2020 , we notice the spaces of the circles of "mathematical cultures" that permeate Brazilian homes.

Keywords: Remote education. Mathematical Education. Numbering practices.

\section{Resumen}

Pretendemos analizar, en este trabajo, el conocimiento matemático movilizado en las estrategias de enseñanza adoptadas por las madres al asistir a las tareas escolares, específicamente para sus hijos, inscritos en las clases del ciclo de alfabetización $\left(1^{\circ}\right.$ a $3^{\circ}$ año) de una escuela pública ubicada en São Carlos SP. Como resultado de la investigación institucional, en términos de justificación, destacamos la importancia del conocimiento informal de los sujetos alfabetizados, a menudo basado en acciones que permean la vida cotidiana. Los datos fueron recolectados desde el enfoque cualitativo, a través de entrevistas virtuales semiestructuradas, debido a la distancia social. Los resultados demuestran que estas mujeres-madres, parece, además del acto de valentía para asumir otra tarea, entre tantas que se responsabilizan en sus hogares, logran sortear las dificultades y recurren a estrategias fundamentales para pensar matemáticamente, aunque no sean convencionales. Como la práctica de contar con los dedos (visualización), hacer la cabeza (cálculo mental) y explorar juegos en internet (usando tecnología), tendencias que buscan desarrollar la autonomía en el aprendizaje. En resumen, identificar, describir y analizar cuál es el aporte central de esta ayuda en casa al aprendizaje matemático de los niños representa, en la lectura interpretativa que hacemos de este momento histórico vivido en 2020, ver los espacios de los círculos de "culturas matemáticas" que permean el Hogares brasileños.

Palabras claves: Enseñanza remota. Educación Matemática. Prácticas de numeración.

\section{Introdução}

Nesse momento de quarentena, em que é reiterado, aos quatro cantos do mundo, o uníssono: "Fica em casa", muitos debates vão sendo expostos e escancaram, como nunca, as contradições presentes nas sociedades de classes do Capital. (CAMILO DOS SANTOS, 2020, p. 12).

Buscamos, com este artigo, dar visibilidade para vivências de famílias de crianças matriculadas no ciclo da alfabetização (1으 ao 3 o ano), as quais viram seus "mundos" e, consequentemente, suas rotinas modificadas drasticamente com os desafios e anseios postos frente ao isolamento social e o iminente processo de terem de assumir mais uma tarefa, para 
além das atividades recorrentes em casa: o auxílio no ensino remoto devido a pandemia de COVID-194.

Neste contexto, esperamos contribuir com as discussões teórico-metodológicas acerca dos processos da educação remota ao abrir canal de diálogo e, consequente, divulgação de aspectos referente ao trabalho de campo que temos empreendido na equipe de investigação, a qual conta com apoio financeiro, por meio da concessão de bolsas de estudos, tanto da Fundação de Amparo à Pesquisa do Estado de São Paulo (FAPESP - Processo: 2019/10100-9) quanto da Coordenação de Aperfeiçoamento de Pessoal de Nível Superior (CAPES).

Assim, perante o contexto de incertezas, a pandemia aflorou uma série de consequências para a vida em sociedade. Vivemos, atualmente, a maior crise de saúde dos últimos tempos, como saldo dela são múltiplas as dimensões afetadas. O trabalho, a família, o mercado, os sistemas de ensino, entre outros, se viram em movimento de mudança, bruscamente. Àqueles e àquelas que pesquisam e precisam, dadas especificidades do objeto e objetivo do trabalho, estar em contato direto com as pessoas, viram-se também afetados e "convidados" para redirecionar suas ações.

Nesta direção, para se entender a investigação que será apresentada, julgamos pertinente resgatar as bases teóricas e o contexto em que os dados foram produzidos para, posteriormente, destacar as informações angariadas via entrevista semiestruturada virtual realizada com um grupo de mães que se autodeclarou responsável pelas tarefas escolares das crianças no período de distanciamento que estamos vivenciando desde a determinação, em 13 de março, pelo governador do Estado de São Paulo (SP), via Decreto № 64.862, a "[...] suspensão das aulas no âmbito da Secretária da Educação [...]" (SÃO PAULO, 2020, p. 1). Para tanto, apoiamo-nos na produção de dados da pesquisa intitulada "LÁ EM CASA ENSINO ASSIM...": ESTRATÉGIAS DE RESOLUÇÃO DE PROBLEMAS ADOTADAS POR FAMÍLIAS DE CRIANÇAS MATRICULADAS NO CICLO DA ALFABETIZAÇÃO.

\section{Enquadramento teórico}

Vivemos em uma sociedade letrada, grafocêntrica e quanticrata, em que as formas de organização, descrição e apreciação da análise de mundo, tal como destaca Fonseca (2014), são marcadas por processos e recursos de quantificação, ordenação, mediação e organização dos espaços e modos com os quais os grupos se desenvolvem, neste caso as famílias que têm de conviver e desenvolver estratégias de acompanhamento e ensino em casa, somando mais um atributo em suas ações diárias. Trabalhos anteriores como, por exemplo, os de Ciríaco e Souza (2011), reforçam o potencial de investigações que buscam conhecer contextos/práticas socioculturais de letramento e letramento matemático inerentes às relações família-escola, o que presumimos também ocorrer no caso de nosso trabalho.

No estudo aqui apresentado, intencionamos analisar, ao menos, três aspectos basilares até a conclusão do trabalho em curso, a saber: 1) "Sentido de número em situações de cálculo"; 2) "Práticas de numeramento das famílias e os contextos culturais de aprendizagem matemática das crianças"; e 3) "Alfabetização matemática na perspectiva do letramento". Sobre os aspectos mencionados, faz-se preciso esclarecer que o referencial teórico para leitura e interpretação dos dados produzidos nos itinerários da pesquisa visa

${ }^{4}$ COVID significa COrona VIrus Disease (Doença do Coronavírus), enquanto "19" se refere a 2019, quando os primeiros casos em Wuhan, na China. Logo: COVID-19. 
auxiliar na percepção sobre a compreensão global e flexível das operações numéricas. 0 intuito é compreender as relações e o desenvolvimento de estratégias eficazes e úteis, a forma como as pessoas se valem dos números para exercício de determinadas atividades, a exemplo: no cotidiano, mundo do trabalho, exercício da cidadania, entre outros.

Assim, para os autores canadenses McIntosh, Reys e Reys (1992, p. 3), o "sentido de número" pode ser definido como um tipo de construção e compreensão dos sujeitos "[...] sobre os números e as operações, juntamente com a capacidade e inclinação para usar essa compreensão de modo flexível, para fazer juízos matemáticos e para desenvolver estratégias úteis para lidar com os números e com as operações".

O sentido de número não é algo que se aprende em um determinado momento da vida, mas sim, "[...] uma competência genérica que se desenvolve ao longo de todo o ensino obrigatório e não obrigatório e ao longo da vida" (ABRANTES; SERRAZINA; OLIVEIRA, 1999, p. 46), precisamos compreender que "[...] a aquisição de sentido de número é um processo evolutivo, gradual, que começa muito antes do início do ensino formal" (MCINTOSH; REYS; REYS, 1992, p. 5) e que, portanto, pode e é adquirido em diferentes espaços e contextos sociais, aos quais incluímos o seio familiar, dadas as interações do processo de educação remota instituído com o isolamento social.

O desenvolvimento do sentido de número é um movimento progressivo e gradativo, exige que a leitura e a interpretação do número atuem em qualquer situação problematizada, permitindo que as crianças lidem de forma flexível e com autonomia de pensamentos na realização de tarefas matemáticas, fazendo o uso de diversas estratégias de resolução de problemas, deixando então, o indivíduo com a capacidade de se mover matematicamente com maior agilidade (MCINTOSH; REYS; REYS, 1992). É, portanto, um conhecimento que pode ser adquirido ao longo da trajetória da vida, não unicamente na escola, motivo pelo qual as famílias podem contribuir para sua formação. "Inclui ainda a capacidade de compreender o facto de que os números podem ter diferentes significados e podem ser usados em contextos muito diversificados" (CASTRO; RODRIGUES, 2008, p. 11).

Cabe destacar que o desenvolvimento do sentido de número é adquirido ao longo de experiências informais e formais, portanto, no âmbito escolar ou fora dele, essa habilidade se constitui em demonstrar capacidade com o cálculo mental, estimativas e quantidades numéricas, assim as crianças precisam conseguir fazer cálculos numéricos mentalmente e em registro escrito.

Dessa maneira, por este poder se apresentar em diversos contextos, principalmente, no ambiente familiar, é um potencial ímpar de espaço-tempo propício para sua fundamentação. Por essa razão, fazemos a defesa da relevância de se conhecer as práticas de numeramento e/ou letramento matemático dos sujeitos responsáveis pelo auxílio nas atividades em casa, este é um princípio basilar para caracterização dos contextos culturais da aprendizagem da criança.

Seguindo os pressupostos de Carraher, Carraher e Schliemann (1988), acreditamos que a possibilidade de se construir uma melhor relação entre família-escola poderá auxiliar no desenvolvimento matemático dos educandos, isso porque temos acompanhado em resultados de pesquisas anteriores, como a destes autores (CARRAHER; CARRAHER; SCHLIEMANN, 1988), que a Matemática escolar vem sendo excludente, o que distancia as práticas culturais de aprendizagem matemática e de mobilização de conhecimentos da família como sendo uma "Matemática" que possa contribuir com as crianças. A defesa que fazemos é que a "Matemática" das famílias pode e exerce, acertadamente, algum tipo de influência no 
sentido de número de seus filhos e precisa ser desvelada na tentativa de superação do estigma do "fracasso escolar", que insiste em dissociar "Matemática cotidiana" da "Matemática escolar" e, portanto, explicita uma relação de poder da dita "acadêmica" em detrimento da "cotidiana". Os autores relatam que:

O ensino da matemática se faz, tradicionalmente, sem referência ao que os alunos já sabem. Apesar de todos reconhecerem que os alunos podem aprender sem que o façam na sala de aula, tratamos nossos alunos como se nada soubessem sobre tópicos ainda não ensinados (CARRAHER; CARRAHER; SCHLIEMANN, 1988, p. 21).

Consequentemente, se faz necessário entender a produção matemática da maioria dos indivíduos e não submetê-los a aceitação da Matemática imposta por uma classe privilegiada e dominante. Os sujeitos vivem em constante aprendizagem, transformando, remodelando e reconstruindo saberes amplamente aplicáveis para situações-problemas do cotidiano (SCANDIUZZI, 2004). Em nosso estudo buscamos legitimar todos os saberes matemáticos mobilizados pelas famílias no momento do auxílio das tarefas matemáticas encaminhadas a casa no período pandêmico, pois compreendemos que: "Não há saber mais, nem saber menos, há saberes diferentes" (FREIRE, 1987, p. 68).

Logo, transformando a Matemática em mecanismo de libertação e não em algo excludente, que restringe o sujeito de participação no mundo, pois "[...] a educação tem caráter permanente. Não há seres educados e não educados. Estamos todos nos educando. Existem graus de educação, mas estes não são absolutos" (FREIRE, 1986, p. 28). Defendemos o posicionamento de que o "não-saber" Matemática, do ponto de vista acadêmico, também é um "saber" Matemática, mas: qual Matemática? É essa que queremos "descortinar" ao tentar compreender a leitura de mundo (matemático) das mulheres-mães que assumem o auxílio no ensino remoto das crianças, tornando visíveis as estratégias e mecanismos que adotam para desempenharem tal função.

Alfabetizar e letrar em Matemática significa ensinar a ler e escrever na linguagem lógico-matemática em uma ampla relação com experiências de uso social de determinadas habilidades que envolvem relações quantitativas, de grandezas/medidas, geométricas e estatísticas, das mais variadas formas e gêneros discursivos e escritos.

Freire (1999) contribui para tal entendimento ao demonstrar ser necessário que o contexto faça parte do ensino dos educandos, a alfabetização deve estar ligada à cultura e atividades produtivas dos sujeitos, a qual entendemos ser, também, aquelas da cultura matemática produzida nas interações entre mãe e filho quando do momento das estratégias de ensino. Sustenta-se, portanto, neste ponto que a Matemática produzida informalmente, ou seja, no ambiente familiar "[...] precisa ser compreendida como um tipo de conhecimento cultural que todas as culturas geram, assim como geram linguagem, crenças religiosas, rituais e técnicas específicas de produção" (KNIJNIK, 2002, p. 35).

Conhecer os modos operantes da mobilização de determinados saberes matemáticos poderá contribuir ao processo da "alfabetização matemática na perspectiva do letramento", uma vez que, de acordo com Ortega e Parisotto (2016), esta representa instrumento de leitura do mundo. Portanto, podemos compreendê-la como uma perspectiva de abordagem da Matemática na escola que supera a simples decodificação dos números e a resolução das quatro operações básicas (ORTEGA; PARISOTTO, 2016). Para as autoras, "[...] a alfabetização, na perspectiva do letramento, inclui as diferentes vivências dos indivíduos inseridos numa 
determinada cultura" (p. 56), uma vez que os indivíduos estão envolvidos em um meio social e se constituem conforme o contexto vivido, com o tempo esses sujeitos vão estabelecendo uma convivência por meio de compartilhamento de experiências significativas.

Seguindo essa linha de raciocínio, ler o mundo pressupõe o entendimento de que a criança chega na escola com conhecimentos matemáticos, embora não sistematizados, mas já em hipóteses de formulação importantes para a construção de significados. Inicialmente, tais significados são atribuídos a partir do contato com a família e nas práticas culturais de aprendizagens informais. Segundo Matos (2002), é indispensável que a Educação Matemática seja trabalhada e associada aos conhecimentos prévios, a realidade e também às necessidades das crianças, já que estas vivenciam no seio familiar contato com números, formas, pesos e situações de possibilidades dos acontecimentos em momentos diferentes no seu cotidiano.

Em 1997, Paulo Freire afirmou que "A leitura do mundo precede a leitura da palavra", de lá para cá, cada vez mais, as experiências escolares e culturais demonstram-nos que isso é pressuposto basilar da ação que se quer ser educativa, por isso educar é um ato de coragem. Coragem de percepção, de amorosidade, de reconhecimento de nossas limitações no espaçotempo dos itinerários da aprendizagem de uma "leitura de mundo" que precede o "ler a palavra".

No campo do letramento matemático, podemos levar a assertiva de Freire como sendo algo fundamental aos estudos da área, uma vez que "letrar matematicamente" implica conhecer e ler o mundo da Matemática em seus aspectos sociais, dos modos de produção que tais conhecimentos possibilitam na "palavramundo" dos conhecimentos matemáticos informais que precedem a linguagem matemática presente no processo de escolarização.

A "leitura" de mundo matemático das mães, em uma analogia ao letramento matemático que estas representam ter e mobilizarem em suas práticas de ensinar e aprender Matemática com seus filhos em casa, demonstram atribuírem significados matemáticos em suas ações por meio da leitura de mundo. O uso social e as interpretações matemáticas das famílias precedem a leitura da matemática escolarizada, sendo assim podemos considerar este tipo de conhecimento como parte integrante do letramento matemático e/ou do numeramento, ambas as denominações são usadas para o mesmo evento ou prática social que se interliga diretamente ao uso específico da Matemática frente às exigências sociais.

O termo "numeramento" é empregado quando se refere às práticas sociais em que se utilizam os conhecimentos matemáticos para se atender demandas "[...] numa sociedade grafocêntrica e quanticrata: cujas práticas socialmente valorizadas pautam-se pela cultura escrita e balizam-se por critérios quantitativos" (FONSECA; RIBEIRO, 2010, p. 5, destaques das autoras). São situações que se associam à vida cotidiana do indivíduo, por meio de eventos ou práticas que necessitam dos códigos, termos e do próprio vocabulário matemático, fomentando a produção de saberes nas ações diárias e que precisam ganhar espaço para ecoar e possibilitar conexões com o que entendemos ser, então, a "realidade dos alunos".

Toledo (2003, p. 55) conceitua numeramento "[...] um amplo conjunto de habilidades, estratégias, crenças e disposições que o sujeito necessita para manejar efetivamente e engajar-se autonomamente em situações que envolvem números e dados quantitativos ou quantificáveis [...]". Grando e Mendes (2007, p. 17), enriquecem a discussão ao destacarem que "[...] essas práticas são altamente valorizadas e legitimadas por determinados grupos sociais se tornando hegemônicas na sociedade".

Cabe ressaltar ainda que isso implica na capacidade do sujeito de colocar e resolver problemas matemáticos em situações diversas, quando passa a exercer uma relação direta 
entre práticas sociais e a Educação Matemática de modo que o conhecimento matemático não esteja apenas ligado ao contexto escolar, mas antes relacionado aos usos específicos de um determinado grupo social como, por exemplo, nas atividades de auxílio nas tarefas escolares das crianças (CIRÍACO; SOUZA, 2011).

A vivência e exploração do conhecimento fomentam o indivíduo a tomada de decisões, aplicação de normas apropriadas e códigos, compreendendo o estabelecimento de regras e contribuindo para o desenvolvimento matemático. Quando o educando aprende por meio da ação cultural, este incorpora os conhecimentos e é capaz de transformar suas ações práticas em eventos de numeramento, por exemplo.

\section{Procedimentos metodológicos e a pesquisa com as famílias}

Perante o quadro do vírus se agravando no Brasil e, particularmente, no Estado de São Paulo, o Decreto Estadual № 64.881, de 22 de março de 2020, estipulou quarentena em todo território paulista. Neste contexto, considerando a Lei Federal no 13.979, de 6 de fevereiro de 2020, "[...] ao dispor sobre medidas para o enfrentamento da citada emergência, inclui a quarentena (art. 2으. II), a qual abrange a restrição de atividades [...] de maneira a evitar possível contaminação ou propagação do coronavírus" (SÃO PAULO, 2020, p. 1a), as aulas presenciais foram suspensas e o contato com a comunidade escolar não fora possível para implementar as ações práticas com as famílias, a qual intencionávamos no projeto inicial.

O distanciamento social fortaleceu a \#FiqueEmCasa. Sem dúvida, em decorrência desta situação, as famílias, agora em casa com as crianças, passaram a ter que reorganizar suas rotinas para o acompanhamento das aulas de forma remota que, em São Paulo, se vale de alguns canais de comunicação como, por exemplo, YouTube no canal do "Centro de MídiasSP", no Facebook na página "Centro de Mídias Educação Infantil e Anos Iniciais", bem como por meio de propostas de atividades encaminhadas no Google Classroom e na TV aberta no canal da Universidade Virtual do Estado de São Paulo (UNIVESP).

Com a colaboração das professoras da escola, especificamente as que lecionam no ciclo da alfabetização (1으o 3 o ano) do Ensino Fundamental (foco da investigação), ocorreu o contato inicial com as famílias. O convite fora encaminhado aos grupos de WhatsApp nos quais as docentes dialogam com pais, mães e responsáveis pelas crianças. Com o aceite em participar, de forma voluntária, após feito contato telefônico e explicitação dos objetivos do estudo, de abordagem qualitativa (BOGDAN; BIKLEN, 2004), como também a dinâmica de colaboração das mulheres-mães (identificadas como principais responsáveis), a produção de dados teve marco inicial. Posteriormente, criou-se grupos individuais no aplicativo de comunicação para diálogo em tempo real, bem como para que fosse possível retirar dúvidas e que se realizassem postagens de vídeos curtos pelas mães, os quais evidenciam interações no momento do auxílio nas tarefas de Matemática.

Além deste aspecto, as bolsistas de iniciação científica e de mestrado realizaram entrevistas virtuais em que se objetivou compreender melhor o cenário, dados estes que serão explorados, em parte, no artigo em xeque. Do quantativo total das famílias que acompanhamos na pesquisa, $90 \%$ das entrevistadas são mulheres, declararam-se como responsáveis diretas pelo auxílio remoto de seus filhos, têm entre 29 e 40 anos. 0 grau de instrução escolar das entrevistadas é de: $70 \%$ com Ensino Médio completo; $20 \%$ possuem Ensino Superior; e 10\% em Ensino Médio incompleto. Em relação à renda familiar, 30\% apresentam de 1 a 2 salários mínimos; $60 \%$ de 2 a 3; e $10 \%$ de 3 a 4 salários mínimos mensais. 
Quadro 1: Caracterização das famílias

\begin{tabular}{|c|c|c|c|c|}
\hline Identificação & Idade & Escolaridade & $\begin{array}{c}\text { Renda média familiar / } \\
\text { Número de pessoas } \\
\text { pertencentes ao grupo } \\
\text { familiar }\end{array}$ & $\begin{array}{c}\text { Quem auxilia no } \\
\text { dever de casa de } \\
\text { Matemática? }\end{array}$ \\
\hline M 1 & 30 anos & $\begin{array}{l}\text { 2o Grau } \\
\text { (Ensino } \\
\text { Médio) }\end{array}$ & $\begin{array}{c}1 \text { a } 2 \text { salários mínimos } / 4 \\
\text { pessoas }\end{array}$ & Mulher (mãe) \\
\hline M 2 & 35 anos & $\begin{array}{l}\text { 20 Grau } \\
\text { (Ensino } \\
\text { Médio) }\end{array}$ & $\begin{array}{c}2 \text { a } 3 \text { salários mínimos } / 4 \\
\text { pessoas }\end{array}$ & Mulher (mãe) \\
\hline M 3 & 37 anos & $\begin{array}{l}\text { 20 Grau } \\
\text { (Ensino } \\
\text { Médio) }\end{array}$ & $\begin{array}{c}2 \text { a } 3 \text { salários mínimos } / 3 \\
\text { pessoas }\end{array}$ & Homem (pai) \\
\hline M 4 & 29 anos & $\begin{array}{l}\text { 10 ano } \\
\text { (Ensino } \\
\text { Médio) }\end{array}$ & $\begin{array}{c}1 \text { a } 2 \text { salários mínimos } / 6 \\
\text { pessoas }\end{array}$ & Mulher (prima) \\
\hline M 5 & 40 anos & $\begin{array}{l}\text { Superior } \\
\text { completo }\end{array}$ & $\begin{array}{c}2 \text { a } 3 \text { salários mínimos } / 2 \\
\text { pessoas }\end{array}$ & Mulher (mãe) \\
\hline M 6 & 37 anos & $\begin{array}{l}\text { 20 Grau } \\
\text { (Ensino } \\
\text { Médio) }\end{array}$ & $\begin{array}{c}2 \text { a } 3 \text { salários mínimos } / 5 \\
\text { pessoas }\end{array}$ & Mulher (mãe) \\
\hline M 7 & 26 anos & $\begin{array}{l}\text { 20 Grau } \\
\text { (Ensino } \\
\text { Médio) }\end{array}$ & $\begin{array}{c}2 \text { a } 3 \text { salários mínimos } / 5 \\
\text { pessoas }\end{array}$ & Mulher (madrasta) \\
\hline M 8 & 36 anos & $\begin{array}{l}\text { 20 Grau } \\
\text { (Ensino } \\
\text { Médio) }\end{array}$ & $\begin{array}{c}3 \text { a } 4 \text { salários mínimos } / 3 \\
\text { pessoas }\end{array}$ & Mulher (mãe) \\
\hline M 9 & 29 anos & $\begin{array}{l}\text { Superior } \\
\text { completo }\end{array}$ & $\begin{array}{c}1 \text { a } 2 \text { salários mínimos } / 4 \\
\text { pessoas }\end{array}$ & Mulher (madrasta) \\
\hline M 10 & 36 anos & $\begin{array}{l}\text { 2o Grau } \\
\text { (Ensino } \\
\text { Médio) }\end{array}$ & $\begin{array}{c}2 \text { a } 3 \text { salários mínimos } / 8 \\
\text { pessoas }\end{array}$ & Mulher (mãe) \\
\hline
\end{tabular}

Fonte: Os autores (2020).

Dentre as entrevistadas, quatro dedicavam-se, quando do momento da entrevista, exclusivamente ao trabalho doméstico [do lar] (M1, M2, M4 e M6) e seis trabalhavam fora concomitante aos afazeres de casa (M3, M5, M7, M8, M9 e M10). Estas mulheres-mães somam responsabilidades extras ao assumirem o papel de auxílio nas atividades remotas encaminhadas pela escola. 
Conforme dito anteriormente, as entrevistas com as mães das crianças transcorreramse de forma a manter o distanciamento social, ou seja, de modo virtual com apoio telefônico, sendo estas gravadas para posterior transcrição. O roteiro de questões postas em apreciação, quando da realização do contato, foi composto por 2 conjuntos de perguntas: o primeiro de caracterização das famílias e sua relação com a Matemática; e o segundo no sentido de compreensão do cenário frente ao novo coronavírus, reorganização da rotina em casa, auxílio nas tarefas escolares (dificuldades e perspectivas).

Destacamos que, para o momento, intencionamos compartilhar dados específicos das respostas que fizeram referência às dificuldades e estratégias de ensino remoto.

\section{Descrição e análise de dados}

Em uma sociedade letrada, grafocêntrica e quanticrata como a nossa, perceber a importância atribuída à Matemática e o "peso" que os conhecimentos oriundos desta área possam ter às famílias é pressuposto basilar para compreensão das práticas de numeramento exercidas no auxílio nas tarefas escolares, isso porque, para as mães entrevistadas, o conhecimento matemático exerce papel fundamental aos processos da vida em sociedade, haja vista que, quando no momento do auxílio, estas recorrem à estratégias aproximadas do modelo escolar, muitas não reconhecem suas próprias formas de saber e seus conhecimentos como sendo de fato Matemática.

\subsection{Dificuldades no acompanhamento das atividades remotas}

As mulheres-mães, quando questionadas sobre o acompanhamento online das aulas e a compreensão das atividades matemáticas encaminhadas para casa, destacaram:

Não sinto dificuldades por enquanto, a não ser semana que vem que começa nos livros, né?!... que eles trouxeram. São os livros que eles estavam trabalhando na escola e agora vão trabalhar em casa, continuação da sala de aula. [...] Eu não entendi como era para achar a resposta. Não sei, daí ela [a filha] ficou sem fazer. Eu não compreendi!

(M1, entrevista concedida em 08/05/2020).

Eu sentia dificuldade para acessar as atividades, mas daí... depois a professora criou um grupo no WhatsApp com os pais da turma e, todos os dias, ela, a partir do meio dia, manda o link com a aula que foi passada de manhã e a gente quando entra, cai direto no YouTube, pra mim foi mais fácil porque às vezes não conseguia acompanhar o que ele estava assistindo, então, quando ela manda esse link e você entra lá no Facebook também pelo centro de mídias você consegue acessar a aula que você perdeu de manhã. É que quando começou o centro de mídias, se você perdesse aula, você não conseguia assistir novamente, ela não ficava gravada, então, eles melhoraram esse recurso, e essa parte da comunicação. A aula fica gravada, então, você pode assistir depois, a professora, pra ajudar manda o link, porque tinha muitos pais que precisam sair para trabalhar o dia inteiro né, então, no meu caso eu não tenho computador da minha casa e o [filho] acompanha pelo meu celular, se ele vai fazer alguma atividade é tudo pelo meu celular, se eu estivesse trabalhando, ele só conseguiria ter acesso a noite e tem pais que está assim, o pai, a mãe está trabalhando, só chega só no final da tarde é... [pensativa], então, a hora que estava lá a aula de manhã a criança pode até ter assistido, mas não consegue entender $100 \%$ para fazer, e os pais... assim, sem acesso não conseguia auxiliar, mas agora ficou melhor ficar gravado, então, ela [A PROFESSORA] manda esse link gravado consegue ter 
acesso a qualquer momento assisti e podem ajudar a criança. (M2, entrevista concedida em 13/05/2020).

No começo eu tinha bastante porque até tive que trocar de celular porque o meu instalava nada não pegava nada eu tive que trocar de celular, mas assim é tranquilo é só o centro de mídia que eu não consigo acessar. O centro de mídia eu fiz acesso, mas eu não consigo daí eu pego pelo YouTube que tem essa opção é mais pelo YouTube mesmo que eu consigo pegar que eu acesso, (...) mas eu estou dando mais ênfase ao material que veio pela matérias do Classroom, no centro de mídia bem pouco. Dificuldade. Só essa mesmo da calculadora e uma outra atividade é de um número que professor estava adivinhando, mas, assim, pra você poder entender eu tenho que te mandar a foto da atividade porque nem eu consigo explicar direito. É um jogo on-line que é a professora, tinha que pensar no número, você tinha que adivinhar, é um vídeo, em vídeo explicando sobre.

(M3, entrevista concedida em 13/05/2020).

A gente "põe" na TV todos os dias e, às vezes, quando vou no sacolão, que lá tem internet, eu fico vendo os vídeos com ela, que a professora me manda. (...) A prima do meu esposo que acessa para mim, aí eu faço com minha filha.

(M4, entrevista concedida em 03/06/2020).

Muita, o site entra, o site sai, aí tem que pôr uma senha que nunca lembro, aí cada hora um caminho diferente, não teve uma lógica, assim: "Oh... o canal vai ser esse", "Vou pôr a atividade essa hora". As crianças fazem, eu assim não devolvi uma lição para a escola que ela fez, eu não sei nem o caminho que eu devolvo essas lições, então, achei bem mal estruturado. (M5, entrevista concedida em 04/06/2020).

No começo sim, mas depois que a professora fez para mim o login e certinho a senha, está tranquilo agora (...) Era de acessar o Google sala de aula, porque eu não tinha um e-mail certo, a senha, então, não tinha como acessar lá direito, aí tinha dificuldade.

(M6, entrevista concedida em 05/06/2020).

Não, tem no YouTube, no site, no centro de mídias. Eu pego e jogo na televisão que fica melhor. (...) Até agora não, porque quando eu assisto o vídeo com ela, eu consigo entender a matéria e ensinar ela a fazer a atividade, então, até agora não, porque as aulas estão sendo bem explicativas. (...) só de ensinar divisão e multiplicação, eu sei o que é, mas não sei explicar. Eu não consigo, não sei onde eu erro. Não consigo explicar para ela que, por exemplo, "2 $\times 2$ " seria "4", aí eu mostro, mas ela não consegue entender, eu não sei onde eu "tô" errando para ensinar e ela entender, sabe?!

(M7, entrevista concedida em 05/06/2020).

Então, como eu estou perdendo o dia certo, às vezes teve uns dias... teve um ou dois dias que não estava mais disponível a atividade no YouTube lá no canal, eu acho que saiu tinha um tempo limite (...) agora está tudo certo, "tá" ok. Agora estou conseguindo achar os vídeos estou conseguindo acessar, a professora coloca no WhatsApp, no grupo da escola mas às vezes eu não sei se expira ou algo assim, só isso que aconteceu. (...) Está super tranquilo é mais a questão que eu me organizar o meu tempo né é só isso.

(M8, entrevista concedida em 04/06/2020).

Ela tá no comecinho assim ao acesso ao centro de mídias não porque a gente tem acesso a internet aqui na TV, então, eu colocava na televisão para assistirmos, mas no comecinho no grupo da sala de aula online eu fiquei com um pouco de dificuldade porque era o Google 
Classroom, então, eu nunca tinha usado, aí eu não estava conseguindo colocar e criar a senha para o [Nome do Filho], mas agora "tá" tranquilo, a gente sempre acompanha as atividades que as professoras vão postando e a gente assistir todas as aulas aqui na TV. (...) Então, eu falo para o [Nome do Filho] para gente levar à sério porque depois que voltar. Se a gente não levar à sério, pegar firme, porque eu sei que tem crianças que não estão assistindo, não têm acesso, eles vão ter essa dificuldade na volta, porque se fica muito tempo sem ir a leitura fica mais devagar, a escrita fica mais confundida eu pego bem firme até antes de começar as aulas mesmo eu já estava dando atividade para o [Nome do Filho] e para minha filha para passar o tempo e para eles também exercitarem.

(M9, entrevista concedida em 05/06/2020).

Para mim assim... [pensativa] ...no meu pensar, tem coisa que é difícil, né?! Aqui dentro de casa tem bastante distração! Em casa, "tá" em casa quer brincar, para pegar eles e colocar em frente da TV para fazer eles prestar atenção é difícil! Porque assim, na sala de aula eles têm o entendimento, né?! Eu creio! O entendimento de que é para estudar e aqui dentro de casa é difícil! É difícil pegar eles e falar agora é hora de estudar: "Ah mãe, eu quero brincar" eles ficam! É bem difícil pegar eles para estudar, mas tem que tentar, né?! No começo fiquei com um pouco de dificuldade, aí eu liguei lá na escola porque não estava conseguindo entrar nas tarefas, tanto é que do mais velho eu consegui entrar faz 10 dias nas tarefas dele, do mais velho, porque eu colocava o R.A [registro acadêmico dos alunos] dele e não conseguia, não ia! Aí entrei em contato com a escola, aí essa semana que passou, retrasada, que eu consegui entrar em contato com a escola e o professor me ajudou, aí eu consegui entrar na tarefa do meu filho e fazer. Agora "tá" tranquilo assim entrar, assistir as aulas, "tá" tranquilo. (M10, entrevista concedida em 08/06/2020).

A pandemia do novo coronavírus colocou inúmeras famílias brasileiras em situações para as quais não se viam "preparadas", a exemplo do trabalho de ensinar Matemática em casa, ficando mais evidente os múltiplos papéis da figura da mulher neste espaço-tempo, assumindo assim, mais uma tarefa. "As mulheres. A quarentena será particularmente difícil para as mulheres e, nalguns casos, pode mesmo ser perigosa. As mulheres são consideradas "as cuidadoras do mundo", dominam na prestação de cuidados dentro e fora das famílias" (SANTOS, 2020, p. 15, destaques do autor). Além disso, o isolamento social e as formas de organização da sociedade frente ao mundo pandêmico trouxe visibilidade ao que já vivíamos: as desigualdades sociais. Quando pensamos nas dificuldades de acesso à internet, por exemplo, de M4 que precisa ir ao "sacolão" de São Carlos-SP para acessar as atividades da filha e ainda depender, por mais que se tenha boa vontade, de terceiros para solicitar visualização às tarefas, estamos a ver isso. Aparentemente, muitos saberes que conhecimentos que consideramos comuns do cidadão do século XXI, como estar conectado, ter e-mail, redes sociais, etc. não é uma realidade presente em um país cuja desigualdade social abarca grande parte da população, como é o caso brasileiro.

Conhecer as dificuldades das famílias torna-se crucial ao processo de constituição da dinâmica do trabalho colaborativo que estamos a fazer com as mães. Isso porque, na medida em que identificamos, via seus relatos iniciais, problemas ligados ao ensino, poderemos, coletivamente, tentar contribuir com o processo de fortalecer relações entre família-escola a partir das interações, nos grupos de WhatsApp criados para acompanhar as estratégias adotadas, como também para se identificar as práticas de letramento matemático recorridas pelos adultos e seus conhecimentos informais mobilizados em situações de cálculo, por exemplo. 
Como vimos, aparentemente, as dificuldades poderão se acentuar com a organização sistematizada do conhecimento [pelo livro didático] e em termos da apropriação dos recursos tecnológicos [plataformas digitais, uso da calculadora, jogos online, etc.] para acesso aos conteúdos programáticos das aulas à distância.

As dificuldades narradas são cruciais para nossa pesquisa, pois possibilitam encaminhamentos futuros, compreender o processo de ensino remoto e fortalecer o vínculo entre família-escola. No caso específico da Educação Matemática, no contexto do trabalho com as famílias, aqui representadas pelas mulheres-mães, compreender como ensinam seus filhos em casa e os recursos recorrentes como estratégias emergentes significa levantar indicadores das possibilidades de se partir da realidade das crianças quando adentramos seus lares, mesmo que à distância, para fazer uso das informações compartilhadas, respeitosamente, na perspectiva de caracterizar o contexto cultural em que a Matemática se faz presente, o que pode ser um caminho para articulação entre a "Matemática do cotidiano" e a "Matemática escolar", como saberes complementares.

\subsection{Estratégias adotadas para acompanhamento das atividades remotas}

Dada a natureza das respostas sobre esse aspecto, parece existir, ao que os dados sinalizam, mobilização de mecanismos importantes, embora não reconhecidos como tal, por parte dos sujeitos letrados [mulheres-mães], no momento de contribuir para a resolução das tarefas matemáticas.

Carraher, Carraher e Schliemann (1988) enfatizam que a Matemática é uma forma de atividade humana. Sendo assim, as mães demonstraram serem letradas matematicamente, pois empregam-na em situações de uso social que envolvem relações quantitativas, de grandezas/medidas, geométricas e estatísticas, das mais variadas formas e gêneros discursivos e escritos como ler rótulos, reproduzir receitas, observar horas utilizando relógio (analógico e digital), entre outros.

Olha, eu busco nos joguinhos, sabe?! Estes de ler e contar, no Play Store, eu baixo e lá [referindo-se ao ambiente de interação com o aplicativo] ajuda muito nas continhas, nas sílabas, ele é muito bom!

(M1, entrevista concedida em 08/05/2020).

Quando ele precisa fazer a continha dupla, né?! Em cima e embaixo, então, ele vai somar, daí ele fala: "aaaaaaah... mãe e agora?" Um exemplo, você tem dois dedinhos, ele quer saber a conta "2 + 3", daí eu falo: "você tem dois dedinhos e você vai GANHAR mais três dedinhos", então, eu ensino ele a contar nas mãozinhas, nos dedinhos ou fazer risquinhos de pauzinhos ali ele vai eliminando ou vai acrescentando.

(M2, entrevista concedida em 13/05/2020).

Para resolver... A gente vai mais com a cabeça mesmo, a gente não pega nenhum recurso, nada mesmo, né?! É mais... na cabecinha, explicação mesmo. Não uso recurso, ela [a filha] mesmo já tem essa facilidade essa coisa de contar no dedo já ir na mente é muito boa pra somar na cabeça, isso já é dela mesmo, ela mesmo utiliza bem isso, eu reforço!

(M3, entrevista concedida em 13/05/2020).

Ensino ela [a filha] a contar nos dedinhos ou com palitinhos. Pego os matérias dela e um caderno reserva e dou para ela fazer risquinhos, somar, diminuir, dividir. 
(M4, entrevista concedida em 03/06/2020).

Leio com ela [a filha], eu faço ela pensar, falo: "Vamos pensar nisso aqui, Oh". Aí eu "ponho" o dedo, número, faço metáfora daquilo que ela precisa fazer, mas no geral eu falo: "Vamos pensar!", para ela. O livro, caderno... só. E tentei da fração com o cubo que tinha em casa. (M5, entrevista concedida em 04/06/2020).

Assim, suponhamos, o menos, né?! Eu falo: "eu tenho tantas laranjas, se eu tirar tanto eu fico com quanto?" Aí ela faz a soma ou no dedo, né?! "Aí eu tiro tanto fico com quantos?" Aí fica assim. Uso palitinho de sorvete, se for menos lápis de cor ou nos dedos mesmo, se for menor número.

(M6, entrevista concedida em 05/06/2020).

De contar nos dedos, por exemplo, a subtração: "olha eu tenho 9. Tenho que tirar 4". Aí ela [a filha] coloca o "9" e eu falo: "agora tira 4, quanto sobrou?" Aí ela fala: "sobrou 5", dessa forma. Na adição também: "eu tenho 7, com mais 3 (filha faz a conta ao lado usando os dedos)". Aí é no de contar nos dedos mesmo. Só uso os dedinhos mesmo.

(M7, entrevista concedida em 05/06/2020).

Ele [o filho] mesmo faz quando tem algum problema, ele mesmo faz o desenho, por exemplo, se tem laranjas, ele vai e desenha, faz risquinhos. Se tem 30 laranjas menos 20 laranjas, ele faz ou ele monta a conta ali também ou vai nos pauzinho e, na maioria das vezes, ele nem usa isso, que na maioria das vezes ele faz de cabeça, ele só olha para os dedos assim [fez um gesto com as mãos] e faz o resultado. Não sei como que ele faz, mas ele só olha e chega no resultado, eu pergunto para ele: "Mas, como você está fazendo essa conta?" Ele mesmo já vai responde: "é assim."

(M8, entrevista concedida em 04/06/2020).

Geralmente, assim, quando é mais continha ou algum problema, a gente acaba lendo. Eu peço para ele [o filho] ler e aí eu peço para ele me explicar o que ele entendeu. Eu questiono: "o que você entendeu [Nome do Filho]?" Aí ele vai falando... Às vezes ele fala: "eu não entendi!" Aí eu tenho que explicar para ele de uma forma que ele entenda. (...) Na maioria os dedos, eu sempre falo para ele, por exemplo, se é uma conta de somar " $8+6$ " eu falo para ele "guardar" 8 na cabeça e contar nos dedinhos o restante, sabe?! Porque é mais fácil para ele guardar uma parte e ir somando.

(M9, entrevista concedida em 05/06/2020).

Cada exercício, tipo um exercício de ler, aí ele [o filho]: "Não... não entendi". Aí eu leio e explico com calma. Uso algum exemplo, sempre faço algum exemplo assim: "Aí [Nome do Filho], você tem quantos carrinhos, aí vem um menino brincar com você, aí você tem que dividir essa quantidade com o menino"... Sempre dou exemplos para ele. O [Nome do Filho] usa muito o cálculo mental, sabe?! Então, não pego nenhum material ou objeto, seria bom pegar um objeto, mas não pego não! Ele sempre faz na cabeça, ele faz a conta no caderno, mas usa o cálculo mental, diferente do meu outro filho o [Nome do Filho], ele é mais difícil, tem que fazer no caderno tudo, já o [Nome do Filho] não, ele já fala: "Aí mãe... é tanto." (M10, entrevista concedida em 08/06/2020).

Com o distanciamento social, as famílias precisaram reorganizar suas rotinas, especificamente as mulheres-mães que compõem esta pesquisa. Ter os filhos mais tempo em casa com elas implicou adequação de tempo em suas rotinas já atarefadas, precisaram 
arrumar momentos situados específicos para as demandas das atividades escolares das crianças, algumas vezes mais de uma e de anos escolares diferentes. Sabemos que a quarentena exige de todos um esforço de se ressignificação, mas de todos os grupos, podemos destacar as mulheres, que além de serem esposas, mães, funcionárias, são neste período "professoras" de seus filhos em tempo integral. É evidente pelas entrevistas que este peso recaí em sua maior proporcionalidade nas mulheres-mães, cabe ressaltar que algumas delas prestam cuidados dentro e fora de seus lares, aumentando ainda mais suas demandas.

Em relação às estratégias no auxílio nas tarefas, é possível verificar que as mulheres entrevistadas procuram vários recursos para ajudar a estimular o desenvolvimento referente ao cálculo das crianças. No ensino remoto [nas atividades numéricas], percebe-se a adoção de estratégias pessoais: umas originam-se das experiências empíricas das mães; outras apoiamse na tecnologia.

Podemos dizer ainda que temos, na prática do ensinar em casa durante o isolamento social, esquemas de ação (contar nos dedos e/ou usar palitinhos) e o cálculo mental (fazer de cabeça), possibilidades de desenvolvimento ao sentido de número que levam à visualização/experimentação, que tomam ora o corpo humano como referência para contagem (dedos das mãos), ora a abstração reflexiva nos procedimentos aritméticos ligados às operações iniciais das estruturas aditivas (adição e subtração), muito embora nem sempre reconhecidas como estratégias quando umas das mulheres (M3) afirma "não" adotar recursos.

Os conhecimentos matemáticos mobilizados pelas famílias, em particular as mães, observados no momento do auxílio das tarefas dos filhos, indicam que estas são letradas matematicamente, ou seja, compreendem características dos mais diversos enunciados matemáticos, a exemplo do trabalho com a resolução de problemas em que recorrem à estratégias de pensamento inferencial com as crianças. Realizam procedimentos de cálculos matemáticos a partir da mobilização de saberes do uso cotidiano e compreendem a importância da Matemática para a vida.

$\mathrm{Na}$ leitura interpretativa que temos feito, da realidade vivenciada agora no isolamento social por este grupo de mulheres, corroboramos com Ciríaco e Souza (2011, p. 53) "[...] as relações entre práticas e condições de letramento e a mobilização de conceitos (...) parecem estabelecer um campo comum de ações que as mães realizam na vida cotidiana, de cuja compreensão buscam se aproximar".

Compreende-se que as atividades do cotidiano das crianças envolvem o raciocínio matemático de forma espontânea. O processo de letramento do aluno não ocorre apenas pela aquisição da escrita numérica, mas em um movimento em que este está inserido em contextos que envolvam o letramento, resolvendo problemas e cálculos, articulando-os com as experiências e vivências na escola e fora dela. Para as mães, as habilidades que os filhos devem ter são ligadas ao uso de números para compreender preços, medidas e efetuar operações básicas, as quais segundo elas são fundamentais para o exercício da vida em sociedade, bem como o exercício da cidadania.

Em suma, pelos relatos das famílias, identificamos algumas estratégias mobilizadas pelas mães para facilitar a aprendizagem de seus filhos, nas atividades de Matemática. Devido a COVID-19, com o isolamento social e suspensão das aulas presenciais, acreditamos que "[...] a responsabilidade pela aprendizagem, ou pelo menos, para uma aprendizagem mais satisfatória da leitura, da escrita e da matemática, acaba ficando, grande parte das vezes, a cargo das famílias e do próprio aprendiz" (ESPÍNDOLA; SOUZA, 2010, p. 71). 


\section{Considerações finais}

Ao longo deste trabalho, propusemo-nos levantar desafios e perspectivas postos à rotina de vida diária de famílias, aqui representadas pela figura materna, a qual teve de assumir, frente o contexto pandêmico, a tarefa de acompanhamento remoto das atividades escolares.

Do lugar que escrevemos e, pela experiência em curso deste estudo, compreendemos que é preciso problematizar a implementação do ensino remoto em ampla articulação com as famílias. Isso porque, além de acompanhar os filhos, pais, mães e responsáveis ainda têm outras atividades que demandam tempo e espaço para sua realização. Não podemos simplesmente pensar um \#FiqueEmCasa e compreender, ingenuamente, por mais que isso faz-se necessário para controle do novo coronavírus, que todas as famílias estão de fato em casa em um país onde a desigualdade social salta aos olhos de modo duro, explícito e cruel.

Frente aos dados problematizados na experiência em questão, torna-se evidente a existência de um tipo de conhecimento matemático presente nas práticas mobilizadas para auxiliar os filhos. Contudo, é preciso caracterizar de forma mais detalhada para se compreender em que sentido estas interferem no desenvolvimento do sentido da aprendizagem das crianças. Afirmamos isso porque, na literatura especializada no campo da Psicologia da Educação Matemática, mais especificamente acerca das atitudes em relação à Matemática, é consensual que a família exerce influência no processo de como ocorre a aprendizagem escolar dos alunos (LOOS, 2003).

Defendemos o posicionamento de que, acertadamente, a família tem um papel importante no apoio ao processo educativo, principalmente neste momento das ações em casa, ou seja, implica o envolvimento direto dos responsáveis no ensino da Matemática e nas outras disciplinas. Entretanto, para auxiliar as crianças nas tarefas, as famílias precisam entender e compreender certas habilidades para auxiliar no desenvolvimento do "sentido de número", a exemplo, ter uma compreensão global e flexível das situações-problemas, desenvolver estratégias diversas para resolver as propostas envolvendo cálculo, entender que os números podem ter inúmeros significados e serem usados em diversos contextos do cotidiano.

As famílias compreendem que ser importante aprender Matemática e que ter o domínio de tópicos específicos de sua natureza implica ter conhecimento para além da leitura e escrita numérica, sendo necessário para a inclusão social e emancipação de seus filhos.

A análise das respostas traz evidências para que possamos afirmar que são letradas matematicamente, ao que tudo indica, existente a percepção da relevância da Matemática na vida e na aprendizagem escolar dos filhos, o que revela reconhecê-la como instrumento de poder. Saber ou não Matemática envolve acesso a usos desta em diversas situações, que podem tornarem-se dispositivos de inclusão e/ou exclusão social. Quando se fala, por exemplo, da adoção de saberes deste campo em atividades laborais, podemos compreender a Matemática escolar como um gerador de possibilidades para o sujeito adentrar ao mercado de trabalho. Meneghetti e Filho (2019, p. 122), destacam que muitas pessoas "[...] em seu cotidiano de trabalho, utilizam práticas relacionadas às maneiras de observar, comparar, organizar, classificar, medir, quantificar e contar, que são práticas próprias do saber/fazer matemático [...]", razão pela qual pode-se explicar a supervalorização de determinados grupos, como em nosso estudo as mães, do conhecimento escolar. 


\section{Referências}

ABRANTES, Paulo; SERRAZINA, Lurdes; OLIVEIRA, Isolina. A Matemática na educação básica. Lisboa: ME/DEB, 1999.

BOGDAN, Robert; BIKLEN, Sari. Investigação qualitativa e educação: uma introdução à teoria e aos métodos. Portugal: Porto Editora, LTDA, 1994.

CAMILO DOS SANTOS, Lívia Maria. "Escorregar não é cair": por quedas com amortecedores. In: SAWAIA, B. B. Apresentação. Boletim “Expressões em tempos de pandemia”. Vol.1. p.12-15. 2020. Disponível em: http://www4.pucsp.br/nexin/expansoes-da-pandemia/expressoes-da-pandemia-vol1.pdf. Acesso em: 27 mai. 2020.

CARRAHER, Teresinha Nunes; CARRAHER, David William; SCHLIEMANN, Analúcia Dias. Na vida dez, na escola zero. São Paulo: Cortez, 1988.

CASTRO, Joana Pacheco de; RODRIGUES, Marina. Sentido de número e organização de dados: textos de apoio para educadores de infância. Biblioteca Nacional de Portugal - Catalogação na Publicação. 2008. Disponível em: https://www.esev.ipv.pt/mat1ciclo/textos/sent_num_net.pdf. Acesso em: 17 jul. 2020.

CIRÍACO, Klinger Teodoro; SOUZA, Neusa Maria Marques de. Um estudo na perspectiva do letramento matemático: a matemática das mães. Vidya (Santa Maria. Impresso), v. 31, p. 43-56, 2011. Disponível em: https://periodicos.ufn.edu.br/index.php/VIDYA/article/view/291/266. Acesso em: 29 set. 2019.

ESPÍNDOLA, Ana Lúcia; SOUZA, Neusa Maria Marques de. Contextos e práticas sócio-culturais de letramento e letramento matemático inerentes às relações família/escola. Zetetiké. v. 18, p. 67-87, 2010. Disponível em:

https://periodicos.sbu.unicamp.br/ojs/index.php/zetetike/article/view/8646670/13572. Acesso em: 14 mai. 2020.

FONSECA, Maria da Conceição Ferreira Reis. A educação matemática e a ampliação das demandas de leitura escrita da população brasileira. In: FONSECA, M. C. F. R. (Org.). Letramento no Brasil: habilidades matemáticas. São Paulo: Global, 2004. p.11-28.

FONSECA, Maria da Conceição Ferreira Reis. Letramento e Numeramento: Educação Matemática e práticas de leitura. Apresentação Seminário do Pacto Nacional pela Alfabetização na Idade Certa PNAIC. 2014. Universidade Federal de Minas Gerais (UFMG), Belo Horizonte (Mg). Disponível em: http://www.ceale.fae.ufmg.br/app/webroot/files/uploads/Palestras\%20Pnaic\%202014/Letramento \%20e\%20Numeramento\%20-\%20Maria\%20da\%20Concei\%C3\%A7\%C3\%A3o.pdf. Acesso em: 26 ago. 2020.

FONSECA, Maria da Conceição Ferreira Reis; RIBEIRO, Vera M. Educação matemática de pessoas jovens e adultas: demandas e contribuições na promoção da apropriação de práticas de letramento. In: Anais do X Encontro Nacional de Educação Matemática, Salvador - BA, 2010. Disponível em: http://www.lematec.net.br/CDS/ENEM10/artigos/PA/Palestra7.pdf. Acesso em: 11 abr. 2019.

FREIRE, Paulo. A importância do ato de ler. 34. ed. São Paulo: Cortez, 1997. 
FREIRE, Paulo. Educação e Mudança. Traduzido por Moacir Gadotti e Lilian Lopes Martin. 12. ed. Rio de Janeiro: Paz e Terra, 1986.

FREIRE, Paulo. Pedagogia da Autonomia: saberes necessários à prática educativa. 12å Ed. Rio de Janeiro: Paz e Terra, 1999.

FREIRE, Paulo. Pedagogia do oprimido. 17ạ ed. Rio de Janeiro, Paz e Terra, 1987.

GRANDO, Regina Célia; MENDES, Jaqueline. (Orgs.). Múltiplos olhares: matemática e produção de conhecimento. São Paulo: Musa Editora, 2007.

KNIJNIK, Gelsa. O saber popular e o saber acadêmico na luta pela terra. Revista da Sociedade Brasileira de Educação Matemática. Educação Matemática em Revista. Ano 9, n. 1, p. 27-39, 2002.

LOOS, Helga Sant'Ana. Atitude e desempenho em matemática, crenças auto-referenciadas e família: uma path-analysis. Campinas, SP. 2003. 296f. Tese (Doutorado em Educação). Universidade Estadual de Campinas - UNICAMP. Disponível em: http://repositorio.unicamp.br/jspui/handle/REPOSIP/253109. Acesso em: 10 mar. 2019.

MATOS, João Felipe. Educação matemática e cidadania. Quadrante, [S. I.], v. 11, n. 1, p. 1-6, 2002. Disponível em: https://quadrante.apm.pt/index.php/quadrante/article/view/289. Acesso em: 26 out. 2020.

MCINTOSH, Alistair; REYS, Barbara J.; REYS, Robert E. A proposed framework for examining basic Number Sense. For the Learning of Mathematics, Canadá, v. 12, n. 3, p. 2-44, 1992. Disponível em: https://flm-journal.org/Articles/94F594EF72C03412F1760031075F2.pdf. Acesso em: 30 out. 2019.

MENEGHETTI, Renata Cristina Geromel; FILHO, Edinei de Oliveira. Etnomatemática e Trabalho Colaborativo na Educação Inclusiva de Adultos no Contexto da Economia Solidária. Revista Latinoamericana de Etnomatemática,12(4), 121-140. 2019. DOI: 10.22267/relatem.19124.38.

ORTEGA, Eliane Maria Vani; PARISOTTO, Ana Luzia Videira. Alfabetização matemática na perspectiva do letramento no Pacto Nacional pela Alfabetização na Idade Certa. Educação em Revista, Marília, v.17, p. 53-62, 2016, Edição Especial. Disponível em:

http://www2.marilia.unesp.br/revistas/index.php/educacaoemrevista/article/view/5845/3982. Aceso em: 12 abr. 2020.

SANTOS, Boaventura de Sousa. A cruel pedagogia do vírus. EDIÇÕES ALMEDINA, S.A. 2020. Disponível em: https://www.cpalsocial.org/documentos/927.pdf. Acesso em: 18 mai. 2020.

SÃO PAULO Governo do Estado. Decreto № 64.862, de 13 de março de 2020. Diário oficial do Estado de São. São Paulo, v. 130, n. 63, p. 01, 2020a. Disponível em:

http://diariooficial.imprensaoficial.com.br/nav_v5/index.asp?c=4\&e=20200331\&p=1. Acesso em: 24 abr. 2020.

SÃO PAULO, Governo do Estado. Decreto № 64.881, de 22 de Março de 2020. Diário oficial do Estado de São. São Paulo, v. 130, n. 57, p, 01, 2020. Disponível em:

http://dobuscadireta.imprensaoficial.com.br/default.aspx?DataPublicacao=20200323\&Caderno=DOE -I\&NumeroPagina=1. Acesso em: 24 abr. 2020. 
SCANDIUZZI, Pedro Paulo. Educação matemática indígena: a constituição do ser entre os saberes e fazeres. In: BICUDO, Maria Aparecida Viggiani; BORBA, Marcelo Carvalho (Orgs). Educação Matemática: pesquisa em movimento. São Paulo: Cortez, p. 186-197, 2004.

SZYMANSKI, Heloísa. A relação família escola: desafios e perspectivas. 2. ed. Brasília: Líber Livro, 2007.

TOLEDO, Maria Elena Roman de Oliveira. As estratégias metacognitivas de pensamento e o registro matemático de adultos pouco escolarizados. 2003. 200f. Tese (Doutorado em Educação) Faculdade de Educação da Universidade de São Paulo, FE/USP. São Paulo, 2003. 